\title{
COTPA 2003 compliance assessment of tobacco vendors and products: current status of an earliest smoke free Indian city
}

\author{
Ankit Chaudhary ${ }^{1}$, Anita Thakur ${ }^{1}$, Tripti Chauhan ${ }^{1}$, Anjali Mahajan ${ }^{1}$, Vijay Kumar Barwal ${ }^{1}$, \\ Shaina Chamotra ${ }^{2}$, Amit Sachdeva ${ }^{1}$, Baljeet Singh ${ }^{1}$
}

\begin{abstract}
${ }^{1}$ Department of Community Medicine, Indira Gandhi Medical College Shimla, Himachal Pradesh, India ${ }^{2}$ Department of Obstetrics and Gynaecology, Kamal Nehru Hospital for Mother and Child, Indira Gandhi Medical College Shimla, Himachal Pradesh, India
\end{abstract}

Received: 24 February 2019

Accepted: 02 April 2019

\section{*Correspondence:}

Dr. Vijay Kumar Barwal,

E-mail: barwalvk@gmail.com

Copyright: (C) the author(s), publisher and licensee Medip Academy. This is an open-access article distributed under the terms of the Creative Commons Attribution Non-Commercial License, which permits unrestricted non-commercial use, distribution, and reproduction in any medium, provided the original work is properly cited.

\section{ABSTRACT}

Background: Tobacco smoking is a global phenomenon, associated not only with health but also with other issues like employment, trade and revenue. However, the ill aspects of tobacco outweigh any productivity related to it. Various regulatory measures have been devised to control this menace at national as well as international level. In India, COTPA-2003 legislation intends to control and regulate tobacco consumption, advertisement and trade.

Methods: The present study assessed the compliance of 157 points of sale and 59 tobacco products to the Sections $5,7,8,9$ and 10 of the smoke free legislation using a structured observational checklist.

Results: In total (41\%) POS were advertising tobacco in one or other form with product showcasing (64\%) being the most common modality of advertisement. Actual advertisement boards were seen at only $14.6 \%$ of POS. About $87 \%$ of the advertisement boards carried a health warning. Loose cigarettes were being sold at about $77 \%$ of the POS. All tobacco products available in the city were observed to display good compliance; however none of the smoke product displayed nicotine and tar content on the pack.

Conclusions: Negligible number of PoS was seen to display an actual advertisement. Almost all tobacco products displayed good compliance to the Act. The striking shortcoming was the absence of nicotine and tar content on the package of the product even after 16 years of enactment. Discrepancies need to be addressed appropriately supplemented with aggressive monitoring of adherence to the Act in order to sustain the smoke free status of the city.

Keywords: COTPA 2003, Smoke free city, Compliance survey

\section{INTRODUCTION}

Smoking whether as a part of religious rituals, as offering to the spirits, as a medicinal use for the ailments or as a recreational habit; has been there for centuries. ${ }^{1}$ Neither any civilization nor any country has been immune to it. In early years of $17^{\text {th }}$ century, tobacco was successfully raised as a cash crop and was even termed as "brown gold". 2 The year of 1913 was the birth of "Modern Cigarette'; R.J. Reynolds introduced the first commercial brand 'Camel' to the world. ${ }^{3}$ Within 150 years of
Columbus finding "strange leaves" in the New World, tobacco was being used around the globe. From the 'snuffing' of 18th century, to the 19th century cigars, to the manufactured cigarettes of the $20^{\text {th }}$ century and to the modern electronic delivery systems; only modality of consumption has altered and the number of smokers has increased exponentially.

Despite studies showing that tobacco in all its forms kills its users, and even non-users, people continue to smoke, and death toll from tobacco use continues to rise with 
more than 7 million people a year dying because of tobacco. $^{4}$ Around $80 \%$ of the 1.1 billion smokers worldwide live in low and middle income countries, where the burden of tobacco related illness and death is heaviest. Tobacco users who die prematurely deprive their families of income, raise the cost of health care and hinder economic development. ${ }^{5}$

India is one of the largest tobacco producing countries and tobacco is an important commercial crop; contributing $\$ 900$ million in the form of foreign exchange and $\$ 3.4$ billion in the form of excise levied on manufactured tobacco. ${ }^{6}$ Tobacco farming provides employment to 45.7 million people directly or indirectly, while bidi manufacturing provides employment to more than 4.4 million workers in India. ${ }^{7,8}$ However the disease burden attributable to tobacco outweighs any economic contribution. The economic cost/loss/burden of smoking globally amounts to nearly 2 trillion dollars each year, equivalent to almost $2 \%$ of the world's total economic output. The majority of the total economic cost of smoking is the lost productivity of those sickened or killed by tobacco and healthcare related expenses of treating smoking-attributable diseases. Notably, this price tag does not include other substantial costs due to second hand smoke, non-combustible tobacco products, the environmental and health damages from tobacco farming; and foremost the immeasurable agony of tobacco victims and their families. ${ }^{9}$ The economic burden attributable to tobacco use from all diseases in India for the persons aged 35-69 accounts for $1.16 \%$ of the gross domestic product, which is $12 \%$ more expenditure on health. ${ }^{10}$ Average personal monthly expenditure on cigarette and bidi in India is Rs1192.5 and Rs 284.1 respectively, and this expense on tobacco procurement comprises approximately $2 \%$ of all expenditure. ${ }^{11,12}$

In order to fight this pandemic WHO came up with Framework Convention on Tobacco Control (FCTC) with its time-tested MPOWER strategy. This package comprises of six practical, affordable and achievable measures to help countries implement specific provisions of the WHO FCTC. ${ }^{13}$ The Government of India being a signatory to this FCTC protocol, framed and passed a legislation titled "Cigarettes and Other Tobacco Products (Prohibition of Advertisement and Regulation of Trade and Commerce, Production, Supply, and Distribution) Act, 2003" (COTPA) to prohibit and regulate tobacco use in India. ${ }^{14}$ The law has further sections intend to protect and promote public health; and encompass evidence based strategies to ensure tobacco control.

As a result of exceptional compliance to this legislation, Shimla, the capital city of Himachal Pradesh was declared smoke free in the year 2010. ${ }^{15}$ However the sustenance of the smoke free title is a challenge as the compliance tends to decline with the passage of time. Therefore, the present study was conducted with an objective to assess the compliance of COTPA 2003, particularly the Sections $5,7,8,9$, and 10 . These sections are associated with the sale and trade of tobacco containing products in Shimla city.

\section{METHODS}

\section{Study area and study sample}

The study was conducted in the tobacco Points of sale (PoS) and tobacco products available in Shimla city. A total of 157 random PoS and 59 tobacco products (smoke and smokeless) were included for study purpose.

\section{Study design}

An observational cross sectional study

\section{Study period}

One year from 01 August 2017 through July 2018

\section{Study tool}

A structured observational checklist adapted from the COTPA 2003 specifications and guidelines; and a guide jointly developed by John Hopkins School of Public Health, Tobacco Free Kids and International Union against Tuberculosis and Lung Disease was used to record the observational findings. ${ }^{16,17}$

PoS and tobacco products were assessed using the structured observational checklist. PoS were observed during peak business hours timings. The PoS were assessed for compliance to Section 5 and tobacco products for Sections 7, 8, 9 and 10 of COTPA 2003 legislation. COTPA 2003 section 5 prohibits advertisement of cigarettes and other tobacco products; advertisement is permissible at places ( PoS, shops and warehouses) and on tobacco products packaging only if they meet certain specifications as clarified under the act. COTPA sections 7, 8, 9, and 10 are concerned with labelling and printing of health warning on tobacco products. ${ }^{14}$ To assess the overall compliance, a few key indicators of each Section were stressed upon and considered for analysis.

\section{Statistical analysis}

The data was collected, cleaned and entered into Microsoft Excel spreadsheet and was transferred to Epi info version 7.2.2.6 software. The discrete variables were expressed in terms of frequencies, proportions and percentages with $95 \%$ confidence intervals. The continuous variables were expressed as means \pm standard deviation. Pearson's Chi-squared or Fisher Exact test was used to test the statistical significance of dichotomous categorical data. Odds Ratio with $95 \%$ Confidence intervals were also calculated to find out the strength of association between exposure and outcome variable wherever required. $\mathrm{P}<0.05$ was considered as statistically 
significant. Two-tailed significance tests were used for all analysis.

\section{Ethical considerations}

Prior permission was taken from Institute Ethical Committee to go ahead with the study. Identifiers were omitted in order to maintain confidentiality and anonymity.

\section{RESULTS}

Out of total 157 PoS of the city, $76 \%$ were permanent shops, $15 \%$ were permanent kiosks and $9 \%$ were temporary kiosks. According to the type of business at Point of sale, tobacco was exclusively sold at 3.8\% PoS, while tobacco was not a major business at about $81.5 \%$ PoS.

The compliance of the PoS for section 5 is shown in Table 1. Only $41 \%$ PoS displayed any kind of advertisement at the site. Product showcasing (64.6\%) was the major form of advertisement at PoS. Actual advertisement was seen at only $14.6 \%$ of shops. Only $30 \%$ of the PoS displaying advertisements confined to the specified size. About $87 \%$ advertisement boards had a health warning incorporated in them. About $77 \%$ of the PoS were found to sell loose cigarettes.

Product showcasing was the most common modality of advertisement of tobacco products as seen at $64.6 \%$ of PoS. This was followed by stickers (15.4\%), dangles $(7.7 \%)$ and boards $(7.7 \%)$.

Table 1: COTPA section 5 compliance of PoS in Shimla city.

\begin{tabular}{|c|c|c|}
\hline \multicolumn{3}{|l|}{ COTPA Section 5 compliance of PoS ( $n=157)$} \\
\hline Indicator & Number $(\%)$ & 95\% CI \\
\hline Advertisement (Advt.) in any form at PoS & $65(41.40)$ & $33.61-49.53$ \\
\hline Advt. board at PoS & $23(14.65)$ & $9.52-21.17$ \\
\hline No loose cigarettes sold & $37(23.57)$ & 17.17-30.99 \\
\hline No smokeless tobacco sold & $36(22.93)$ & $16.61-30.30$ \\
\hline \multicolumn{3}{|c|}{ Section 5 compliance of PoS having advertisement board $(n=23)$} \\
\hline Advt. of specified size & $7(30.43)$ & $13.21-52.92$ \\
\hline Advt. not illuminated & $23(100)$ & $85.18-100$ \\
\hline Advt. not displaying brand name or promotion & $23(100)$ & $85.18-100$ \\
\hline Advt. not exceeding to full body of board & $2(8.70)$ & $1.07-28.04$ \\
\hline Health warning in advt. board & $20(86.96)$ & $66.41-97.22$ \\
\hline \multicolumn{3}{|c|}{ Section 5 compliance of PoS having health warning in advt. board $(n=20)$} \\
\hline Health warning in specified colour/background & $14(70)$ & $45.72-88.11$ \\
\hline Health warning of specified size & $10(50)$ & $27.20-72.80$ \\
\hline Health warning at specified place & $13(65)$ & $40.78-84.61$ \\
\hline Health warning in applicable Language & $20(100)$ & $83.16-100$ \\
\hline
\end{tabular}

Table 2: COTPA section 5 comparison of PoS of Shimla city.

\begin{tabular}{|c|c|c|c|c|}
\hline Indicator & $\begin{array}{l}\text { Permanent } \\
\text { Shop }(n=120)\end{array}$ & $\begin{array}{l}\text { Permanent } \\
\text { Kiosk }(n=23)\end{array}$ & $\begin{array}{l}\text { Temporary } \\
\text { Kiosk }(n=14)\end{array}$ & P value \\
\hline Advt. at PoS & $47(39.2)$ & $9(39.1)$ & $9(64.3)$ & 0.200 \\
\hline Advt. board at PoS & $11(9.2)$ & $6(26.1)$ & $6(42.9)$ & $0.001^{*}$ \\
\hline No loose cigarettes sold & $26(21.7)$ & $7(30.4)$ & $4(28.6)$ & 0.544 \\
\hline No smokeless product sold & $30(25)$ & $4(17.4)$ & $2(14.3)$ & 0.637 \\
\hline \multicolumn{5}{|c|}{ Section 5 compliance comparison of POS having advt. Board $(n=11, n=6, n=6)$} \\
\hline Advt. of specified size & $5(45.5)$ & $2(33.3)$ & 0 & 0.242 \\
\hline Advt. not illuminated & $11(100)$ & $6(100)$ & $6(100)$ & - \\
\hline Advt. not displaying brand name or pack shot & 0 & 0 & 0 & - \\
\hline Advt. not displaying promotional message & 0 & 0 & 0 & - \\
\hline Advt. not exceeding full body of board & $2(18.2)$ & 0 & 0 & 0.478 \\
\hline \multicolumn{5}{|c|}{ Section 5 compliance of different $P o S$ having health warning in advertisement $(n=9, n=6, n=5)$} \\
\hline Health warning in specified colour or background & $8(88.9) \quad 3$ & 50) & $3(60)$ & 0.273 \\
\hline Health warning of specified size & $5(55.6)$ & 50) & $2(40)$ & 1.000 \\
\hline Health warning at specified place & $6(66.7)$ & 66.7) & $3(60)$ & 1.000 \\
\hline
\end{tabular}


Table 3: COTPA sections 7, 8, 9 and 10 compliance of tobacco products $(n=59)$.

\begin{tabular}{|llllll|}
\hline Indicator & Number $(\%)$ & $\mathbf{9 5 \%} \mathbf{C I}$ & $\begin{array}{l}\text { Smoke } \\
\mathbf{n = 4 2}(\%)\end{array}$ & $\begin{array}{l}\text { Smokeless } \\
\mathbf{n = 1 7}(\%)\end{array}$ & P value \\
\hline Any kind of health warning on pack & $59(100)$ & $93.94-100$ & $42(100)$ & $17(100)$ & - \\
\hline Warning of Smoking/Tobacco kills on pack & $59(100)$ & $93.94-100$ & $42(100)$ & $17(100)$ & - \\
\hline Health warning in specified font and colour & $59(100)$ & $93.94-100$ & $42(100)$ & $17(100)$ & - \\
\hline Health warning placed below picture on pack & $57(96.61)$ & $88.29-99.59$ & $42(100)$ & $15(88.2)$ & 0.079 \\
\hline 'Warning' word in specified font and colour & $57(96.61)$ & $88.29-99.59$ & $42(100)$ & $15(88.2)$ & 0.079 \\
\hline $\begin{array}{l}\text { Content covering appropriate area in front } \\
\text { panel }\end{array}$ & $57(96.61)$ & $88.29-99.59$ & $42(100)$ & $15(88.2)$ & 0.079 \\
\hline $\begin{array}{l}\text { Health warning placed at specified place on } \\
\text { pack }\end{array}$ & $58(98.31)$ & $90.91-99.96$ & $42(100)$ & $16(94.1)$ & 0.288 \\
\hline Health warning in specified language & $57(96.61)$ & $88.29-99.59$ & $40(95.2)$ & $17(100)$ & 1.000 \\
\hline $\begin{array}{l}\text { Health warning not compressed or distorted or } \\
\text { obscured }\end{array}$ & $55(93.22)$ & $83.54-98.12$ & $38(90.5)$ & $17(100)$ & 0.314 \\
\hline No promotional message on pack & $59(100)$ & $93.94-100$ & $42(100)$ & $17(100)$ & - \\
\hline No promotional insert inside pack & $59(100)$ & $93.94-100$ & $42(100)$ & $17(100)$ & - \\
\hline No deceiving descriptor in pack & $57(96.61)$ & $88.29-99.59$ & $40(95.2)$ & $17(100)$ & - \\
\hline No special packaging other than specified & $59(100)$ & $93.94-100$ & $42(100)$ & $17(100)$ & - \\
\hline Nicotine and Tar content mentioned on pack & 0 & - & - & - & - \\
\hline
\end{tabular}

Table 2 shows the comparison of different types of PoS regarding compliance of COTPA section 5. Advertisement boards were observed significantly more at Compliance of permanent shops was marginally better than kiosks for most of the indicators; however such difference was not found to be statistically significant.

On an average 2 out of 6 key indicators were being fulfilled. None of the $23 \mathrm{PoS}$ displaying advertisement in the city had good compliance to the section 5 (Only 23 PoS out of 157 had an advertisement board, rest 132 did not have any physical board).

To assess the compliance to COTPA 2003 sections 7, 8, 9 and 10; a total of 59 products (42 smoke and 17 smokeless) available in Shimla city were observed for compliance of various provisions under these sections. Out of 42 smoking tobacco products, 23 were cigarettes while 19 were bidis.

Above $90 \%$ compliance was seen for the all indicators except the mentioning of tar content on the smoking tobacco products. None of the tobacco product mentioned tar and nicotine content on pack showing absolute non compliance to Section 10. All products displayed specified health warning on the pack. Overall tobacco products were observed to have good compliance to the compliance indicators. Both smoking and non-smoking products were observed to have good compliance to the act with no statistically significant difference between the two (Table 3).

Good overall compliance was seen for the sections 7, 8, 9 and 10 of the act among tobacco products. All products available in the city were observed to display good compliance for the key indicators with about nine key indicators being fulfilled across the category.

\section{DISCUSSION}

In the present study mixed compliance to COTPA section 5 was observed. Out of 157 PoS, 65 displayed some kind of tobacco advertisement. None of the PoS having some advertisement at shop displayed good compliance for this section. Similarly, in Chandigarh only $3.8 \%$ of shops were compliant with all the indicators of Section $5 .^{18}$

Tobacco advertisement in any form was seen at $41.4 \%$ shops of the city; which was similar to Chandigarh where advertisements were present in $42.3 \%$ of the shops. ${ }^{18} \mathrm{~A}$ three jurisdiction study observed all PoS displaying advertisement in one or other form; while in Mysore 88.5\% PoS displayed advertisement showing low level of compliance. $^{19,20}$ High compliance was seen in Bihar, Kerala, Maharashtra and Rajasthan where 82\%, 94\%, $78 \%$ and $93 \%$ PoS venues were observed without advertisement respectively. ${ }^{21-24}$

In Shimla city the compliance to these sections was better as $83.4 \%$ of the PoS did not display any tobacco advertisement board; whereas in Ahmedabad, more than half $(53 \%)$ of the shops did not have any tobacco advertisement. ${ }^{25}$ Out of those advertising tobacco products, only $30.4 \%$ advertisements were of specified size. Similar compliance was observed by Goel et al where oversized boards were observed at about $94 \%$ of sites. ${ }^{20}$ In contrast, only $15.4 \%$ and $25 \%$ of advertisement boards exceeded recommended size in Chandigarh and Mysore respectively. ${ }^{18,19}$ However in Ahmedabad, only $15.3 \%$ of the POS had complied with the size of advertisement board. ${ }^{25}$ 
Health warning which is mandatory under the act was seen in $87 \%$ of the advertisement boards. Similar findings were observed in other studies where more than $80 \%$ ( $83 \%$ to $94 \%$ ) advertisement boards were found to be compliant to this criterion. ${ }^{18,19}$

Good overall compliance was seen for the sections 7, 8, 9 and 10 of the act among tobacco products. All products were observed to display good compliance for the key indicators with about 9 out of the key indicators being fulfilled across the category. The mean compliance of tobacco products to the various indicators was about $78.3 \%$ in a study conducted by Goel et al. ${ }^{18}$

Health warning on pack of tobacco products was observed in $100 \%$ products available in city which was similar to a study conducted in Rajasthan. ${ }^{21}$ In Chandigarh and Mysore, the products compliant with act were in tune of $80.8 \%$ and $86.2 \%$ respectively. ${ }^{18,19}$ Specified warning of "smoking/tobacco kills" was seen on $100 \%$ products. In Bengaluru, $100 \%$ products had a label as specified by the act; however it did not follow all the specifications. ${ }^{26}$ Warning was seen $80.8 \%$ and $86.2 \%$ products in Chandigarh and Mysore respectively. ${ }^{18-19}$

We found that warning content covering appropriate (at least $85 \%$ ) area in both panels was $96.6 \%$ of the products, while only $79.2 \%$ of the brands in Bengaluru, $73.1 \%$ in Chandigarh and $84.5 \%$ in Mysore fulfilled this indicator respectively. ${ }^{18-20}$

Health warning was not compressed/distorted/obscured in 93.2\% tobacco products; similar findings were observed by Goel et al where $92.3 \%$ products showed compliance for this indicator. ${ }^{18}$ In contrast, in a study conducted by Laxmi, only $6.3 \%$ of products displayed compliance for this indicator. ${ }^{19}$

Cent percent of products did not have any promotional message or insert in the pack; in contrast in South India promotional messages in $90.3 \%$ and inserts in $39.5 \%$ packs were observed. ${ }^{19}$ Deceiving descriptor on pack was observed in mere $3.4 \%$ of the products. This was quite less than the study conducted in Mysore where such descriptor was seen in $48.7 \%$ of the products. ${ }^{19}$ All products in the city were packed in accordance with the provision of the act; in Mysore $6.3 \%$ products were observed to have special packaging. ${ }^{19}$

\section{CONCLUSION}

Although actual advertisement boards were seen at only $14.6 \%$ of PoS, yet none of the board complied with the specifications mentioned in the act. Another matter of concern was the sale of loose cigarettes at about more than three-quarters of the PoS; confirming violation of the act. Another major violation of the act was selling of loose cigarettes by the vendors of the city. This must be dealt seriously and major penalties must be imposed on violators. As the kiosks displayed poor compliance to provisions of the act, attention must be paid towards them and they should be directed sternly to ensure compliance to the act. Even after lapse of more than 15 years since the act came into existence, the tobacco product manufacturers are still not displaying the nicotine and tar content on their products. The authorities must take this issue sternly. Since tobacco is known to cause a spectrum of diseases literally sparing no organ system of the human body, other diseases apart from cancer like heart diseases can also be included in the warning message on the signage as well as packing of tobacco products. This is expected to produce more deterrent effect on both users and non users. Innovative approaches like plain white packaging of tobacco products making them less appealing to users and children may be incorporated into provisions of the act. Frequent compliance surveys must be conducted in order to see deficiencies, so that corrective countermeasures can be taken appropriately and timely.

\section{Limitations}

Owing to the limited one time observation of a facility for duration of 30 to 60 minutes, the possibility of underestimation of the violation of the Act cannot be ruled out.

\section{ACKNOWLEDGEMENTS}

We acknowledge the support of administrative authorities of Shimla City for granting necessary permission for the study.

\section{Funding: No funding sources \\ Conflict of interest: None declared}

Ethical approval: The study was approved by the Institutional Ethics Committee

\section{REFERENCES}

1. Gately I. Tobacco: A cultural history of how an exotic plant seduced civilization; $1965 ; 1-5$.

2. Jordan L E. Jamestown, Virginia, 1607-1907: An Overview. University of Virginia. Available: https://web.archive.org/web/20021017223417/http:/ curry.edschool.virginia.edu/socialstudies/projects/jv c/overview.html. Accessed 12 November 2018.

3. Samet J. The Tobacco Epidemic: An Historical Overview, Johns Hopkins Bloomberg School of Public Health. Available: http://ocw.jhsph.edu/ courses/GlobalTobaccoControl/PDFs/Lecture1.pdf. Accessed 12 November 2018.

4. Mackay J, Eriksen M. The tobacco Atlas: World Health Organization; 2002. Available from: https://www.who.int/tobacco/media/en/title.pdf. Accessed 12 November 2018.

5. WHO Tobacco fact sheet March 2018. Available: https://www.who.int/news-room/factsheets/detail/tobacco. Accessed 12 November 2018. 
6. Indian Mirror. Indian Tobacco Industry Internet. Available: http://www.indianmirror.com/indianindustries/tobacco.html. Accessed 12 November 2018.

7. Tobacco board India: Annual Report 2016- 2017. Ministry of Commerce. Government of India; 2017. Available from: http://tobaccoboard.com/tbdata/ publicationsfiles/AR16-17ENG.pdf. Accessed 12 November 2018.

8. Tobacco in India: Food and Agricultural Organization. Available from: http://www.fao. org/docrep/006/y4997e/y4997e0h.htm. Accessed 12 November 2018.

9. Drope J, Schluger N, Cahn Z, Drope J, Hamill S, Islami F, Liber A, Nargis N, Stoklosa M. The Tobacco Atlas. 6th ed. American cancer society; 2018.

10. Economic Burden of tobacco related diseases in India. New Delhi: Ministry of Health and Family Welfare, Government of India; 2014. Available from: https://mohfw.gov.in/node/3236. Accessed 12 November 2018.

11. Global adult tobacco survey second round, India 2016-2017 report. Available from: https://mohfw. gov.in/newshighlights/global-adult-tobacco-survey2-gats-2-india-2016-17-report. Accessed 12 November 2018.

12. Selvaraj S, Srivastava S, Karan A. Price elasticity of tobacco products among economic classes in India, 2011-2012. BMJ Open. 2015;5(12).

13. MPOWER in action. Defeating the global tobacco epidemic. Available at: https://www.who.int/ tobacco/mpower/publications/mpower_2013.pdf.

Accessed 12 November 2018.

14. Cigarette and Other Tobacco Products (Prohibition of Advertisement and Regulation of Trade and Commerce, Production, Supply and Distribution) act-2003. New Delhi: Ministry of Health and Family Welfare, Government of India; 2003.

15. Tobacco free initiatives in Himachal Pradesh: Smoke free Shimla. Shimla: Department of Health and Family Welfare, Government of Himachal Pradesh, Department of Health and Family Welfare 2010. Available from: http://hphealth.nic.in/ pdf/2010CaseStudySmokeFreeHimachal.pdf.

Accessed 12 November 2018.

16. Assessing compliance with smoke free laws, Second edition: A "how to" guide for conducting compliance studies. International Union against Tuberculosis and Lung Disease. 2014. Available: https://www.theunion.org/what-we-do/publications/ technical/english/compliance-guide_v4smallerfile. pdf. Accessed 12 November 2018.
17. Guidelines for Law Enforcers for effective implementation of Tobacco Control Laws 2013. Ministry of Health and Family Welfare Government of India; 2013.

18. Goel S, Sardana M, Jain N, Bakshi D. Descriptive Evaluation of Cigarettes and Other Tobacco Products Act in a North Indian City. Indian J Public Health. 2016;60(4):273-9.

19. Laxmi. Assessment of Current Level of Compliance to COTPA (The Cigarette and other Tobacco Product Act) 2003 in Mysore District of State of Karnataka, India. Int J Preven Curat Comm Med. 2016;2(1).

20. Goel S, Kumar R, Lal P, Tripathi J, Singh RJ, Rathinam A, Christian A. How compliant are tobacco vendors to India's tobacco control legislation on Ban of advertisements at point of sale? A three jurisdictions review. Asian Pac J Cancer Prev. 2014;15(24):10637-42.

21. Jain M, Chauhan M, Singh R. Compliance Assessment of Cigarette and Other Tobacco Products Act in Public Places of Alwar District of Rajasthan. Indian J Public Health. 2016;60:107-11.

22. Compliance with the Cigarette and Other Tobacco Products Act (COTPA) Results from 2012 and 2013: Maharashtra. Available: https://www.global tobaccocontrol.org/sites/default/files/FS_2014_COT PA_maharashtra.pdf. Accessed 12 November 2018.

23. Compliance with the Cigarette and Other Tobacco Products Act (COTPA) Results from 2012 and 2013: Kerala. Available: https://www.global tobaccocontrol.org/sites/default/files/FS_2014_COT PA_kerala.pdf. Accessed 12 November 2018.

24. Compliance with the Cigarette and Other Tobacco Products Act (COTPA) Results from 2012 and 2013: Bihar. Available: https://www.global tobaccocontrol.org/sites/default/files/FS_2014_COT PA_bihar.pdf. Accessed 12 November 2018.

25. Govil S, Dhyani A, Mall AS. Compliance assessment of tobacco vendors of Ahmedabad city to India's Tobacco control legislation. Indian J Comm Health. 2016;28(4):374-7.

26. Habbu SG, Krishnappa P. Assessment of implementation of COTPA-2003 in Bengaluru city, India: A cross-sectional study. J Indian Assoc Public Health Dent. 2015;13:444-8.

Cite this article as: Chaudhary A, Thakur A, Chauhan T, Mahajan A, Barwal VK, Chamotra S, et al. COTPA 2003 compliance assessment of tobacco vendors and products: current status of an earliest smoke free Indian city. Int J Community Med Public Health 2019;6:2157-62. 